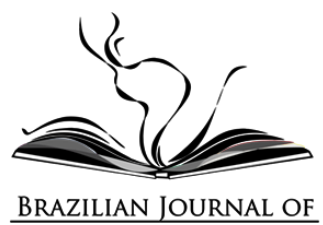

\title{
A LITERATURA NAZISTA NA AMÉRICA (ROBERTO BOLAÑO)
}

\author{
LITERATURA NAZI EN AMÉRICA (ROBERTO BOLAÑO) \\ NAZI LITERATURE IN THE AMERICAS (ROBERTO BOLAÑO)
}

\author{
Lincoln Secco' (iD \\ Universidade de São Paulo, Brasil
}

Resumo: Literatura Nazista na América é um livro publicado em espanhol em 1996. Ele foi traduzido no Brasil em 2019. São 31 estórias em 13 partes e um epílogo. Esta resenha discute o uso que o autor faz dos gêneros literários (conto, novela, relatos jornalísticos etc) e a combinação de personagens fictícios e reais.

Palavras Chave: Fascismo; Nazismo; Romance Fantástico; Literatura Chilena

Resumen: Literatura Nazi en América es un libro publicado en español en 1996. Fue traducido en Brasil en 2019. El libro tiene 31 historias divididas en 13 partes y un epílogo. Esta reseña discute el uso que el autor hace de algunos géneros literarios (cuentos, novelas, reportes periodísticos etc.) y la combinación de personajes ficticios y reales.

Palabras-Clave: Fascismo; Nazi; Romance fantástico; Literatura Chilena

Abstract: Nazi Literature in the Americas was first published in Spanish in 1996. In 2019, It was translated into Brazilian Portuguese. In this book, there are 31 stories divided into 13 sections and an epilogue. This review discusses how that book's author uses literary genres (tale, novel, journalistic stories etc) and the combination he makes of fictional and real characters.

Keywords: Fascism; Nazism; Fantastic Romance; Chilean Literature 
A literatura pode conter em suas entranhas a barbárie. Ainda que isso seja um truísmo, o livro do escritor chileno Roberto Bolaño (1953-2003) está longe disso.

Ele não se limita a escrever uma antologia de escritores fictícios de direita; nem a compor um cânone sinistro da literatura; nem mesmo um ensaio moral sobre o nazismo. Decerto, todas essas características lá estão. Como Jorge Luis Borges, as personagens de Bolaño, suas obras e suas vidas se imbricam com personalidades reais da cultura e do poder. As pontes entre arte e crime, literatura e política são construídas a partir da noção de cumplicidade: uma expressão da circularidade entre a alta sociedade e o underground típica dos movimentos fascistas.

Bolaño construiu biografias fictícias de subcelebridades literárias. Elas passam por espaços em que aristocratas decaídos e aproveitadores do submundo se encontram; cruzam em suas vidas com pessoas reais do mundo político e, particularmente, cultural. A ralé colhida em todas as classes para servir tanto ao crime quanto à repressão de Estado incorpora um matemático amador; uma duquesa decaída; um bajulador, secretário e amante; o "populista de direita" que escreve seus "sonetos proletários"; a feminista e escultora conceitual que convive entre militares e torturadores chilenos; o traficante de drogas que comercializa obras de arte; o ator superdotado do cinema pornô; o filósofo nazista; o coronel semiólogo; o chefe da torcida do Boca Juniors que atua na repressão enquanto faz poesias; o capitão reformado, autor de livros bucólicos e ecologistas...

Somente a mistura de realidade e imaginação dá conta de um movimento irracional como o fascismo. A vida de uma poeta argentina, a imaginada Edelmira Thompson Mendiluce que ascendeu por casamento à oligarquia terrateniente, é muito mais crível do que a breve alusão que Bolaño faz ao contista brasileiro (este real) Rubem Fonseca, um ex-delegado de polícia e ideólogo de um think thank da extrema direita 
brasileira financiado por empresas estrangeiras para preparar um golpe no Brasil.

Aqueles escritores são sempre pessoas de um convívio aceitável. Muitas vezes medíocres, em casos excepcionais importantes como Pound ou D'Annunzio. Transitam das altas rodas às sociedades secretas e explanam ideias confusas sem que isso cause perplexidade. Antes passam como excentricidades. Uma delas, a de servir de elo entre a mansão e o bas-fond, entre o roubo legalizado (a mais-valia) e o crime.

Pelo fascismo imaginário de Bolaño desfilam filósofos incompreendidos, poetas sem renome, coristas de quinta categoria, decoradores, marginais, lacaios, ermitões, psicopatas, um membro do esquadrão da morte brasileiro e o próprio Rubem Fonseca, protégé e costas quentes da ditadura. Mas as personagens de Literatura Nazista na América não são meras alegorias da violência.

O Cobrador de Rubem Fonseca, por exemplo, é um poeta lúmpen, justiceiro e assassino que se une a uma entediada mulher rica. No conto falta verossimilhança a essa transição brusca de um homem que só conseguia estuprar e estrangular para o amante que aprende a amar. Ao submeter-se ao amor ele poderá então passar dos homicídios individuais para o terror coletivo, talvez numa alusão aos grupos de esquerda que Fonseca sempre perseguiu. Ele lê a política revolucionária como sintoma de uma doença e união da aristocracia com o lumpemproletariado. Trata-se da típica projeção de si mesmo no outro que os fascistas sempre promovem.

A trajetória de brutalidade do personagem de Fonseca é envolta por uma prosa naturalista e chula. O cobrador adentra o apartamento de uma ricaça jovem e o estupro tem uma descrição detalhada para que o conto funcione. Entre o seu mundo e o dos que lhe "devem" não há incertezas nem uma zona de penumbra e transição. Em Bolaño, o excêntrico não penetra o andar de cima só pela brutalidade explícita. Há uma área comum e cinzenta entre o estabelecido e o outsider, entre a estética 
reconhecida e o Kitsch. Ele não necessita descrever a exposição fotográfica de Ramírez Hoffman, torcionário, covarde e sequestrador que escrevia poemas em latim no ar com um caça Messerschmitt da Luftwaffe. Há algo de fascista na própria escrita de Fonseca, uma violência sexual que não é só do conteúdo e sim uma violação de formas que permitem-no transitar entre o gosto do crítico literário e a fruição simplória do leitor fascista. Por isso Fonseca coube muito bem como um personagem em poucas linhas de Bolaño e o contrário não seria possível ou convincente.

São detalhes colhidos en passant que denunciam a cumplicidade de uma artista com o nazismo. Mas seu fundamento literário não é necessariamente uma inclinação natural das personagens. Nem todas elas se comprazem em salas de tortura, metem-se em brigas de rua ou se engajam decididamente na extrema direita política. Em algumas a violência explícita está contida no lar recôndito: os remédios psiquiátricos e o espancamento da mulher pelo marido são revestidos por vernissages, edições de autor ou de luxo e poemas de pretensão épica. É nas situações banais que a barbárie se mostra. Ela é parte do próprio modo de produção da própria arte que pressupõe aquilo que todas as personagens têm em comum: a indiferença pelo sofrimento humano.

Num romance póstumo de Bolaño, O Terceiro Reich, um jovem alemão circula num povoado espanhol nos anos 1980; convive com uns desclassificados locais enquanto flerta com a dona também alemã do hotel em que se hospedam os turistas. Sobe e desce de elevador o tempo todo como se o movimento fosse uma metáfora do seu trânsito na escala social. Mas em qualquer situação ele é ponderado e contido. Até suas relações íntimas com a namorada sueca são desprovidas de encanto ou excesso: "Hicimos el amor" ele registra telegraficamente no seu diário. Reservadamente ele se corresponde com pessoas de uma confraria internacional desconhecida que simula jogos bélicos. Seu passatempo quase profissional é elaborar estratégias em que a Alemanha poderia ter vencido a Segunda Guerra Mundial. O nome do jogo: o Terceiro Reich. 
Ecos daquela outra obra estão neste A Literatura Nazista na América. $O$ personagem Harry Sibelius é autor de fanzines de wargames. O piloto da força aérea chilena, torturador e performer, é também protagonista do livro Estrela Distante (1996). Literatura Nazista na América pode ser lido como uma antologia de crônicas, contos ou verbetes imaginados de um dicionário. As revistas inventadas se combinam a publicações anticomunistas existentes como, por exemplo, as seleções do Reader's Digest. Ao final há uma lista de autores, obras e editoras fascistas, o que confere à ficção verossimilhança e à verdade um caráter ficcional, porquanto algumas atrocidades na "luta contra o comunismo" jamais são comprovadas oficialmente.

São 31 estórias em 13 partes e um "epílogo para monstros" (subdividido em três itens). O tom oscila entre o discurso onisciente e distante e a aceleração do enredo em primeira pessoa. As formas são múltiplas como o conto, a novela, o relato jornalístico e a descrição "científica". E nenhuma forma se fixa. A mistura de gêneros literários se inscreve na própria produção imaginária das personagens de Bolaño. No início, o autor narra a trajetória da citada Edelmira Thompson Mendiluce e descreve detalhadamente sua transfiguração artística do ensaio "A Filosofia do Imobiliário" de Edgar Allan Poe. Ela descreve o quarto de Poe e o bom gosto na decoração de ambientes. De passagem conhecemos seu contato com Adolf Hitler numa viagem a Berlim. O realismo, a sobriedade da narração e o encadeamento com os capítulos seguintes nos remetem à ideia de um romance. Mas em outras partes desfilam magos, mercenários, miseráveis, abusos familiares, autores de ficção científica norte-americana e o leitor se vê perante uma descrição fria de verbetes de enciclopédia. Ao final, "Ramírez Hoffman, O Infame" torna o livro um irônico thriller policial tendo como pano de fundo a hipocrisia e a crueldade banal da ditadura de Pinochet no Chile.

O livro é de 1996 mas foi escrito imaginariamente num futuro próximo. Seu olhar para o passado parece estranhamente dirigido ao nosso 
presente. E devemos levar a sério o seu título. Ele fala da América, a mesma que em algum momento passou a ser governada por fascistas no Brasil, nos Estados Unidos...

\section{Referências}

Bolaño, Roberto. A Literatura Nazista na América. Trad. Rosa Freire D’Aguiar. São Paulo: Companhia das Letras, 2019.

Bolaño, Roberto. El Tercer Reich. Barcelona: Debolsillo, 2018.

Bolaño, Roberto. La literatura nazi en América. Barcelona: Seix Barral, 1996.

Bolaño, Roberto. Nazi Literature in the Americas. New York: New Directions, 2008. 